\title{
GCU
}

Glasgow Caledonian

University

University for the Common Good

\section{Optimizing the real-world impact of rehabilitation reviews: increasing the relevance and usability of systematic reviews in rehabilitation}

Kayes, Nicola M; Martin, Rachelle A; Bright, Felicity A; Kersten, Paula; Pollock, Alex

Published in:

European Journal of Physical and Rehabilitation Medicine

DOI:

10.23736/S1973-9087.19.05793-9

Publication date:

2019

Document Version

Author accepted manuscript

Link to publication in ResearchOnline

Citation for published version (Harvard):

Kayes, NM, Martin, RA, Bright, FA, Kersten, P \& Pollock, A 2019, 'Optimizing the real-world impact of rehabilitation reviews: increasing the relevance and usability of systematic reviews in rehabilitation', European Journal of Physical and Rehabilitation Medicine, vol. 55, no. 3, PMID 30990002 , pp. 331-341. https://doi.org/10.23736/S1973-9087.19.05793-9

\section{General rights}

Copyright and moral rights for the publications made accessible in the public portal are retained by the authors and/or other copyright owners and it is a condition of accessing publications that users recognise and abide by the legal requirements associated with these rights.

Take down policy

If you believe that this document breaches copyright please view our takedown policy at https://edshare.gcu.ac.uk/id/eprint/5179 for details

of how to contact us. 
Optimising the real-world impact of rehabilitation reviews: increasing the relevance and usability of systematic reviews in rehabilitation

Nicola M. Kayes ${ }^{1 *}$, Rachelle A. Martin ${ }^{2}$, Felicity A.S. Bright ${ }^{1}$, Paula Kersten ${ }^{3}$, Alex Pollock $^{4}$

${ }^{1}$ Centre for Person Centred Research, School of Clinical Sciences, Auckland University of Technology, New Zealand

${ }^{2}$ Rehabilitation Teaching and Research Unit, University of Otago and Burwood Academy of Independent Living, New Zealand

${ }^{3}$ School of Health Sciences, University of Brighton, United Kingdom

${ }^{4}$ Nursing, Midwifery and Allied Health Professions Research Unit, Glasgow Caledonian University, United Kingdom

\section{Corresponding author}

Nicola Kayes, $\mathrm{PhD}$

Centre for Person Centred Research

School of Clinical Sciences

Auckland University of Technology

90 Akoranga Drive

Auckland

New Zealand

Email: nkayes@aut.ac.nz 


\begin{abstract}
Background: Despite a growing portfolio of rehabilitation reviews, uptake of review findings into practice remains slow, with review findings perceived to be lacking in relevance and usability for stakeholders. Key aspects of review design, production and dissemination have been identified to contribute to this knowledge translation (KT) gap.
\end{abstract}

Aim: To identify strategies relevant to rehabilitation review design, production and dissemination which have the potential to optimise uptake of review findings into practice.

Results: Two strategies are discussed, drawing on case examples of existing rehabilitation reviews, including: 1) involving stakeholders in review design, production and dissemination; and 2) moving towards theory-based, mixed methods review design. The merits of these strategies are discussed with reference to the unique and specific characteristics of the rehabilitation context, where there is complexity inherent in the multiple interacting components across population, intervention, context and implementation processes.

Discussion: Moving towards theory-based, mixed methods reviews which involve stakeholders may be a critical first step in supporting uptake of review findings into rehabilitation practice. Doing so also has the potential to support advances in knowledge and practice in rehabilitation through theory development, as well as creating the context for evidence-based practice.

Key words: knowledge translation, stakeholder participation, systematic review 


\section{INTRODUCTION}

While considerable resource is allocated to generating new knowledge, uptake of research findings is slow, with research taking 17 years or more to find its way into practice. ${ }^{1}$ This is frequently referred to as the 'know-do gap ${ }^{,-5}$ and has led to a growth in research seeking to better understand the complexities of the knowledge translation (KT) process, seeking to identify strategies for more effective transfer of knowledge into policy and practice. There is increasing recognition of the roles and responsibilities of researchers and research institutes to explicitly consider knowledge translation from the outset of their research, with a detailed explanation of pathways to research impact now routinely sought as part of grant acquisition activities and national research evaluation frameworks. Consistent with this movement, the Cochrane Collaboration have developed a KT strategy and framework ${ }^{6}$, which complements the Cochrane's Strategy to $2020^{7}$, setting the agenda for culture change towards Cochrane becoming a 'KT-oriented organisation where uptake and use of our evidence is at the forefront of our minds from the beginning and throughout the review production process' (p.3). ${ }^{6}$

Research has identified a range of complex factors which influence uptake of systematic review findings into policy and practice including review attributes, user skill, knowledge, attitude and confidence, and organisational structures. ${ }^{8-13}$ There are a number of barriers relevant to review production and dissemination which are potentially modifiable. These can be broadly grouped into three themes including relevance, usability and capability. Lack of perceived relevance of systematic reviews are frequently cited as a barrier to uptake ${ }^{89}$, including that reviews are too narrow in topic and scope. ${ }^{13}$ Even when in scope, lack of timely access to review findings hindered uptake. ${ }^{8}$ Perceived $u$ sability (or utility) includes the lack of clear digestible summaries of findings ${ }^{11}$, low perceived usefulness ${ }^{12}{ }^{13}$, lack of data relevant to local context ${ }^{10}$, limited detail regarding benefits, costs and other data relevant to application of findings in policy and practice. ${ }^{12}{ }^{13}$ Finally, capability refers to factors relevant to the skills and knowledge of users. For example, a number of studies have indicated that lack of familiarity with reviews, their methods and use is a key barrier to uptake. ${ }^{811} 13$ Consistent with this, users report low confidence in their skills to assess and interpret review findings. ${ }^{8} 9^{11-13}$ It has also been noted that organisational factors may play a role with structures, such as limited resource allocation for training in review methods, as potentially indicative of the (lack of) value ascribed to review evidence as a key source of data for policy and practice. 81213 
Notwithstanding the range of complex reasons for the limited uptake of systematic review findings into policy and practice, a number of barriers to uptake can arguably be addressed in the context of review design, production and dissemination. In this paper, we discuss two strategies with a primary focus on increasing relevance and usability of rehabilitation reviews including: 1) stakeholder involvement in review design, production, and dissemination; and 2) a move to theory-based, mixed methods systematic reviews. It is also our contention that these strategies may also serve as a mechanism for improving capability for review use within policy and practice. This paper does not attempt to provide a concrete 'how to' of stakeholder involvement or review methods. There are already a number of comprehensive methodological papers on these topics. ${ }^{14-17}$ Rather, this paper will critically consider the role of these strategies in supporting uptake of systematic review evidence in rehabilitation policy and practice, drawing on existing examples in rehabilitation.

\section{STAKEHOLDER INVOLVEMENT IN REHABILITATION REVIEWS}

In addition to the argument that people with a health condition, their family and other informal carers, health professionals, funders, guideline developers, policy-makers and members of the public (collectively referred to as 'stakeholders') have a moral right to contribute to health research, stakeholder involvement may be critical to optimise the uptake of research findings into practice. ${ }^{18}$ Stakeholder involvement in health and social care research has an impact across the research continuum (i.e. in the early stages, during the research process, and when engaging in dissemination activities) with their involvement contributing to the construction of meaningful, context-appropriate, culturally-relevant, credible, user-friendly research findings. ${ }^{19}{ }^{20}$ Given this, the expectation of stakeholder involvement in research from project commencement is now embedded in research policy and funding guidelines internationally. ${ }^{21}$ To support researchers there have been a number of conceptual and methodological contributions to the field ${ }^{22-26}$ including research exploring some of the challenges, and facilitators, of how to meaningfully involve stakeholders in research and related recommendations. ${ }^{192728}$ Current evidence concurs that tenets central to good practice in stakeholder involvement include careful planning, clear communication, defined roles and responsibilities, training and financial reimbursement. ${ }^{21}$ 29-31 Furthermore, respect, trust, confidentiality and clarity are considered essential principles for successful involvement. $^{31} 32$ 
Consistent with this broader mandate for stakeholder involvement in research, there are increasing calls to involve stakeholders in the planning, production and dissemination of systematic reviews. ${ }^{8} 102533-39$ In July 2017, the Cochrane Collaboration published a Statement of Principles ${ }^{40}$ which are founded on principles of equity, inclusion and partnership, and acknowledge the value of stakeholder involvement for producing evidence, making evidence accessible, advocating for evidence and building a sustainable organisation. In an effort to support methodological advance and capability building related to stakeholder involvement in reviews, Pollock and colleagues have been undertaking the ACTIVE project ${ }^{37}$, aiming to produce learning resources to support systematic review authors to involve stakeholders in their reviews. As part of this project, a comprehensive scoping review has been completed, mapping the evidence base relating to stakeholder involvement in systematic reviews and describing key features concerned with how stakeholders have been involved to date. ${ }^{37} 39$ This scoping review informed the production of a valuable Cochrane Training learning resource, 'Involving People', which includes a range of useful resources, guidance documents and case studies describing practical examples of how to involve people throughout the review process. ${ }^{16}$

The role of stakeholder involvement in systematic review design, production and dissemination is not a new idea. Indeed, Bastian (1994) highlighted that one of the founding principles of the Cochrane Collaboration is ensuring access and argued this should not be limited to access to the final product, but rather that stakeholder (referred to as 'consumers' by Cochrane) participation be integrated into the process more broadly. ${ }^{41}$ Despite this, in 2016 a review of evidence for stakeholder involvement in Cochrane and other organisations, concluded that, while there are some examples of involvement being integrated throughout the review process, often involvement remains limited to commenting on completed reviews or protocols, or assisting in provision of plain language summaries. ${ }^{42}$ This review $^{42}$, and the more recent review by Pollock and colleagues ${ }^{39}$ which focussed on involvement within individual systematic reviews, concur that, to date, stakeholder involvement in systematic reviews has been inconsistent in terms of who, when and to what extent stakeholders are involved in the review process.

In general, systematic reviews in rehabilitation are recognised as more complicated than reviews focussed on medical interventions (e.g. pharmacological interventions). ${ }^{15} 43$ This is because rehabilitation generally involves a complex intervention, with resultant challenges 
relating to definition, implementation and description of the intervention, as well as complexities in study methods and outcome selection and assessment. ${ }^{44-48}$ The Medical Research Council of the United Kingdom suggests that a complex intervention may involve a number of interacting components (active ingredients), intervention targets (such as individual, family, practitioner, organisational and/or system), outcomes (both proximal and distal), and may be tailored to population and context. ${ }^{49}$ A rehabilitation intervention may possess complexity across all these levels. For example, an intervention aiming to improve physical activity in people with Multiple Sclerosis (MS) may involve a number of interacting components (physical, behavioural and social), require behaviour change for both the rehabilitation practitioner delivering the intervention and the person with MS, have the potential to impact outcomes across all levels of the International Classification of Functioning, Disability and Health ${ }^{50}$, may need to be tailored by MS type (relapsingremitting, secondary progressive, chronic progressive) and, to optimise effect, should account for the unique and specific needs, preferences and context of the individual with MS and their family. This adds complexity not only in the conduct of rehabilitation trials, but also in synthesising evidence from those trials in a systematic review. These complexities and challenges arguably enhance the potential impact of stakeholder involvement in rehabilitation reviews, as additional decisions and judgements are necessitated throughout the review process. Stakeholder input when clarifying, for example, the review focus, scope, definitions and search terms, outcomes and interpretation of findings, may have a valuable impact on the production of reviews which are useful, with potential for real-world impact. In rehabilitation specifically, evidence of stakeholder involvement in systematic reviews is sparse - either because stakeholders have not been involved, or due to poor reporting of their engagement and role in the review process. For example, an exploration of the 291 systematic reviews which mentioned some degree of stakeholder involvement, identified in the scoping review carried out by Pollock et al. ${ }^{39}$, indicates that around 19\% (56/291) may focus specifically on rehabilitation topics. Of these, a majority relate to mental and behavioural disorders $(30 \%$, $17 / 56)$, or musculoskeletal disorders $(12 \%, 7 / 56)$. In line with the results of the scoping review, reporting within these rehabilitation reviews of who was involved and in what way was generally very poor. There are however, some case examples (see Box 1 and Box 2) that can help to illustrate the diversity of ways in which stakeholders can be engaged in the review process in a rehabilitation context. 
In these examples, Pollock et al. drew on guidance from Boote ${ }^{51}$ taking a pre-determined and structured approach to engagement, and incorporating consensus building strategies. This contrasts with Cullen et al. who appeared to take less structured approach, although specific details regarding the format of their stakeholder meetings were limited. In both cases, the authors argue that stakeholder involvement deepened and strengthened their review processes. They contributed a diversity of ideas and opinions to improve review methods, ensured data extraction processes would result in relevant data and outcomes, and aided construction of key messages that would be usable and digestible to other key stakeholders. As such, within both examples the impact of involvement of stakeholders potentially supports uptake of systematic review evidence by enhancing the relevance and usability of the review findings to key audiences.

Although the authors of both these examples proposed that the involvement of stakeholders in their review had a beneficial impact, neither carried out any formal evaluation of this. This lack of evaluation of impact is consistent with the findings from the ACTIVE project, which found that none of 32 reviews (which had provided good descriptions of methods of stakeholder involvement) reported any formal evaluation. ${ }^{39}$ Given the potential for stakeholder involvement to increase the upfront costs of review production, formal evaluation may be necessary to better understand the opportunity-cost of their involvement and therefore the level of resource allocation that is warranted. Clearly, in order to optimise stakeholder involvement for real-world impact on rehabilitation reviews, strategies for evaluating impact must be implemented. Such strategies will require careful consideration of the recording and reporting of stakeholder involvement. Despite the existence of a number of tools, frameworks and guidance relating to reporting of stakeholder involvement (e.g. ${ }^{53}$ ), current evidence highlights that reporting is currently inconsistent and often inadequate. ${ }^{39}$

In both our selected examples, stakeholders contributed to an update of a previously completed review. While it could be argued that this inherently limits the role that stakeholders can play in setting the context and agenda for the review, both review teams were able to be responsive to changes in review direction and protocol in response to stakeholder feedback. For example, Pollock et al. ${ }^{54}$ developed a new method of intervention categorisation in collaboration with their stakeholder group while Cullen et al. ${ }^{55}$ expanded their review question and scope to include mental health conditions. 
While the examples presented here are review updates, evidence demonstrates that stakeholder involvement can occur across all stages of the systematic review process. ${ }^{16} 39$ There are also examples of stakeholder involvement informing decisions both before and after the systematic review process. For example, Synnot et al. (2017) provide an excellent example of engaging stakeholders in a review prioritisation process in order to inform planning of new reviews. ${ }^{56}$ They engaged 151 stakeholders (consumers and professionals) in an online survey to identify research priorities in health communication and participation, resulting in the selection of five topics which were subsequently conducted as Cochrane systematic reviews. ${ }^{57}$ In contrast, Martin et al. (2015) provide an example of involvement which occurred after completion of a systematic review relating to screening for dementia, with a patient and public event offering opportunities to contextualise the findings of a systematic review to a particular audience. ${ }^{58}$

In practice, rehabilitation involves a range of stakeholders including patients, families, and a diverse range of health professionals. In vocational rehabilitation, this also extends to include employers and workers compensation (or related) systems. This is reflected in the diverse range of stakeholders involved in both the Pollock et al. and Cullen et al. reviews. Indeed, Keown et al. define stakeholders as 'a consumer of the research findings, an audience member who has a stake in the topic being investigated, or a potential decision maker (policy and/or practice) within the context of their role' (p.67). ${ }^{35}$ As such, exactly who might be engaged in any given review process will depend on the intended aim and purpose of the review, as well as the desired impact or audience. It is important however to recognise that different stakeholder groups have competing motives and drivers ${ }^{59}$ which may need to be actively managed through the course of the review. This may include having a transparent discussion regarding who holds the decision-making power through the process, and/or drawing on explicit consensus building strategies such as those used by Pollock et al. ${ }^{54}$ While this may add complexity to the review process, successfully navigating these differences through the review process may ultimately increase the potential for uptake of review findings across a diversity of settings. There is also a need to recognise that stakeholder input will inevitability privilege the views of those engaged in the process, and that some stakeholder groups may face barriers to involvement. ${ }^{60}$ Recognising these barriers and implementing strategies aimed at diverse and inclusive involvement may be important to mitigate against this. 
Consistent with the conclusions from the examples above, Keown et al. argue that stakeholder involvement in reviews has the potential to increase relevance (at least in part due to researchers' increased understanding of stakeholder needs, preferences and context), support capability building in review methods, and increase stakeholder confidence in their ability to read, interpret and apply review findings. ${ }^{35}$ Furthermore, they suggest stakeholder involvement enhances the credibility of findings for other stakeholders. These wide-ranging benefits all point to the potential for stakeholder involvement in reviews to optimise uptake of review findings into practice.

Given the inherent complexity in rehabilitation interventions and the resultant challenges in research synthesis in face of that complexity, stakeholder involvement may be particularly relevant. Indeed, involving stakeholders in rehabilitation reviews may help researchers see beyond the question of what works, to more complex, nuanced and real-world questions which appear to be a priority for stakeholders. It is this that is the key driver for our second recommended strategy discussed below.

\section{THEORY-BASED, MIXED METHODS REVIEWS}

Frequently interventions with established efficacy fail to translate to real world effectiveness. ${ }^{61-64}$ It has been argued that, in the process of controlling for threats to validity ${ }^{43}$ ${ }^{65}$, randomised controlled trials may fail to adequately account for the complexity inherent in interventions where effects are dependent on context, the unique and specific characteristics of individuals receiving the interventions, and relevant implementation processes. ${ }^{146566}$ Systematic reviews have been subject to the same criticism. ${ }^{14}{ }^{67}$ Indeed, it has long been recognised that Cochrane's focus on "What works?" or "Does it work?" may fail to address other questions relevant to complex health systems ${ }^{68}$ and of importance to stakeholders. Snilstveit (2012) argues that focusing only on the average effects of a population in the context of a complex intervention, which may not behave the same across settings and populations, constrains the use of systematic reviews in policy and practice. ${ }^{69}$ Further, she argues that the lack of systematic reporting of other policy-relevant data such as how, why and in what contexts something works may prevent uptake or result in misuse of review data.

The value of systematic reviews is largely derived from their ability to provide clear guidance to policy makers or health care planners regarding effectiveness of a given intervention. However, frequently in rehabilitation, conflicting findings or heterogeneity in sample and/or outcomes means that review findings are inconclusive, reducing their value to decision 
makers. Further, the unyielding focus on adherence to systematic review guidelines can result in tight inclusion criteria which does not reflect the realities of real-world practice, reducing transferability of review findings across settings, contexts and populations. Indeed, this tight inclusion criteria potentially compounds the already limited scope of included trials. For example, Kersten et al. (2010) reported that in order to achieve homogeneity in trials, a great many people have to be excluded. This restrictive selection significantly reduces generalisability of trial findings with often only $10-15 \%$ of the total population with the condition being included. ${ }^{43}$

While involvement of stakeholders as described above goes some way to bridging this gap between research and practice, it is possible that the narrow focus on effectiveness and the desire for homogeneity as a gold standard may lead to tensions between the intent to be responsive to stakeholders and the need to adhere to rigid quality standards. Indeed, research priorities identified by stakeholders are rarely formed as simple, answerable research questions. For example, Synnot et al. acknowledged that the topics identified through their priority setting exercise with stakeholders were not searchable, answerable research questions, or conducive to systematic review methods. ${ }^{56}$ Similarly, Pollock et al. (2012) noted that the research priorities relevant to life after stroke identified by stakeholders were broad topic areas rather than well-formed review questions. ${ }^{70}$ In both cases, the translation of a topic into an answerable review question that is consistent with systematic review guidelines may risk missing the nuance of the topics identified by stakeholders. Further, given the level of complexity inherent in a rehabilitation intervention (such as that described above in the example of a physical activity intervention for people with MS) it is clear that a narrow focus on questions of effectiveness are unlikely to sufficiently address the multitude of questions stakeholders need answered and to support uptake of those interventions into practice.

It has been argued that reviews would be more relevant and usable if they drew on programme theory and integrated a broader range of evidence. ${ }^{69} 7172$ Indeed, this has been recognised by Cochrane where a Qualitative and Implementation Methods Group has been formed to explore opportunities and methods for integrating a broader range of evidence to support implementation processes. ${ }^{73}$ The central thesis of these arguments is that reviews which integrate a broad range of evidence to develop portable theory would be more able to respond to questions about how and why interventions work in different settings. This, in turn, may be formative to knowledge translation activities. 
A plethora of approaches to research synthesis have been developed in response to limitations of conventional systematic reviews. ${ }^{144}$ Realist review (sometimes referred to as realist synthesis) is one review approach which has gathered momentum due to its capacity to produce relevant and usable findings. ${ }^{171}$ Realist reviews explicitly seek to understand complexity through exploring the question of a programme theory (an understanding of how an intervention works and what the key active ingredients are hypothesised to be) and a rich and practical understanding of the conditions under which an intervention is likely to be most effective. ${ }^{14}$ Context-mechanism-outcome (CMO) configurations are used as a heuristic device to guide the synthesis of a range of data types ${ }^{75-77}$ and can inform a more targeted approach to implementation in local contexts. ${ }^{78}$ Snilstveit argues for theory-based, mixed methods systematic reviews - an approach consistent with the general tenets for realist review. ${ }^{69}$ She proposes two approaches to theory-based reviews including: 1) an effectiveness plus review, which remains largely consistent with conventional systematic review, but includes some modifications to design, such as extracting additional data on how, why, costs, risks, and other relevant contextual factors; and 2) effectiveness plus with parallel review, where other review modules are carried out in parallel to a more conventional review so they can be read together to inform policy and practice. In an effectiveness plus review, the included studies remain the same as conventional review, but additional details may be gathered from other sources, including grey literature. In an effectiveness plus with parallel review each parallel review component may have entirely different review question, search strategy and eligibility criteria to increase their potential to answer questions of relevance to decision makers.

There are some excellent examples of these approaches in the literature outside of rehabilitation. For example, Greenhalgh et al. (2007) expanded an earlier Cochrane review ${ }^{79}$ exploring effectiveness of school feeding programmes by conducting a realist synthesis of included papers ${ }^{80}$ (consistent with what Snilstveit describes as an effectiveness plus review, albeit with the two components published separately). They justified the approach by arguing that while their Cochrane review had found positive effects on growth and cognitive performance, the design, context, and population characteristics were too varied. This variation meant that further exploration was warranted to determine the conditions under which success (or failure) was more or less likely. The result is a nuanced discussion of theories and processes derived from included studies which could be formative to future development of school feeding programmes. More recently, Whittaker et al. (2016) conducted a multi-phased, comprehensive review aiming to evaluate interventions designed 
to reduce repeat unintended teenage pregnancies. ${ }^{81} 82$ This review was unique in that a number of review modules were conducted in parallel, each drawing on a different approach to synthesis (e.g. meta-analysis, meta-regression, thematic synthesis, realist synthesis, etc.). Each module had a guiding review question ranging from questions of effectiveness and predictors to mechanisms and perceived acceptability; and these questions underpinned the search strategy and eligibility criteria for included studies. The final phase focused on bringing the review modules together into an overarching narrative synthesis. This approach is consistent with an effectiveness plus with parallel review approach, but advances on this with the final overarching synthesis and interpretation.

We have, arguably, been slower to draw on a pluralistic approach to review design in rehabilitation. There are many examples of reviews which tackle pertinent rehabilitation topics drawing on individual review methodologies other than conventional systematic reviews (e.g. realist review ${ }^{83}$, metasynthesis ${ }^{84}$ ). However, examples of reviews which bring together different review traditions in topics relevant to rehabilitation are limited. There may be a number of reasons for this, such as ongoing debates regarding the extent to which systematic and realist reviews are ontologically compatible ${ }^{65}$, or the prevailing dominance of the positivist and biomedical paradigms which privilege effectiveness studies over other forms of evidence. ${ }^{85}$ Further, despite the development of realist review guidelines ${ }^{17}$, they are inherently complex to carry out. Unlike conventional systematic reviews they rely on an iterative, flexible and responsive approach and require a high level of expertise and skill in critical reflexivity. ${ }^{7678}$ Regardless, we are starting to see some examples emerging relevant to rehabilitation such as the example provided in Box 3. In this example, Brown et al. (2016) draw on both meta-analysis and realist review to explore the effectiveness of family-based interventions to support physical activity in children. ${ }^{86}$ The realist review augments metaanalysis findings with a more in-depth consideration of context, mechanism and outcome. This results in explicit recommendations for policy and practice regarding interventions strategies most likely to be effective, and contexts in which they are most likely to be activated.

\section{[Insert Box 3 about here]}

As with stakeholder involvement, theory-based, mixed methods reviews, such as realist reviews, have the potential to improve relevance and usability of review findings in policy and practice. Furthermore, they may contribute to ongoing theory development work in 
rehabilitation, enabling clinicians to tailor their approach to optimise effect based on the unique and specific population, context and implementation characteristics in their setting.

\section{COMBINING STAKEHOLDER INVOLVEMENT AND THEORY-BASED, MIXED METHODS REVIEWS FOR KNOWLEDGE TRANSLATION IN REHABILITATION}

In the above, we have argued that a) involving stakeholders in review design, production and dissemination and b) moving towards theory-based, mixed methods systematic reviews has the potential to increase uptake of review findings into rehabilitation policy and practice by generating more relevant and usable reviews. The Cochrane KT framework identifies a range of key themes representing processes (or actions) they argue to be necessary for knowledge translation. Table 1 maps these themes against the potential benefits of stakeholder involvement and theory-based, mixed methods review design.

[Insert Table 1 about here]

Table 1 clearly shows the explicit role these two strategies have in supporting uptake of review findings into rehabilitation practice. Indeed, they have the potential to address many of the barriers cited in the introduction of this paper. Ideally, the two strategies would be used in combination. For example, theory-based, mixed methods systematic reviews will be more useful to stakeholders if they have been engaged in the process of identifying key questions of importance to them at the outset. Similarly, involving stakeholders in an effectiveness review is more likely to result in uptake if there has been an attempt to understand the complexities of real-world practice drawing on theory-based, mixed methods design.

The 'black box' of rehabilitation is a phrase used to describe the complexities inherent in the rehabilitation process. ${ }^{44}$ As described above, rehabilitation is by nature a complex intervention; invariably involving a multidisciplinary team, family, and a range of other stakeholders. It includes any number of active ingredients, involves transition across settings, is often delivered in the context of multimorbidity, and frequently requires engagement over a sustained period of time. Given this complexity, and the need for more robust guidance on why, when, how, and to whom specific interventions should be applied, researchers have been undertaking work to better understand the key active ingredients and mechanisms at play in rehabilitation interventions to both underpin more robust treatment theory in 
rehabilitation, and inform rehabilitation practitioners in treatment selection. ${ }^{87}$ Indeed, this work answers a longstanding call for theory development in rehabilitation. ${ }^{88}$ As such, theorybased, mixed methods reviews which involve stakeholders may not only support uptake of review findings into practice, but may also support these ongoing research endeavours through contributing theory-informed and evidence-based knowledge advance in rehabilitation.

Finally, it is useful to consider the role that reviews which draw on this combination of strategies have in embedding evidence-based practice in a more meaningful way. While evidence-based practice in its original form argues for the integration of the latest research evidence, clinical experience and patient needs and preferences ${ }^{89} 90$, research evidence is frequently privileged over clinician and patient expertise in putting that into practice. ${ }^{89}$ It is possible that focusing solely on reviews of effectiveness without input from stakeholders may perpetuate the problem. As such, being explicit about the unique and specific expertise that stakeholders can contribute to design, production and dissemination of rehabilitation reviews, and drawing on a broader range of evidence to help to make sense of practice realities, has the potential to contribute to a more meaningful engagement with evidence-based practice as it was original intended.

\section{CONCLUSION}

Uptake of review findings into rehabilitation policy and practice is crucial to optimise service delivery and outcomes. While there are a range of complex factors which constrain integration of review findings into practice, there are some aspects of review design, production and dissemination which could be enhanced to support uptake. Responding to calls for action to support KT, Cochrane has developed a KT framework to underpin the development of related strategies. We have discussed two strategies relevant to rehabilitation reviews including involving stakeholders throughout the review process, and drawing on theory-based, mixed methods review design. These strategies have the potential to improve relevance and usability of review findings, optimising the likelihood of their uptake in rehabilitation policy and practice. Given the complexity inherent in the development and delivery of rehabilitation interventions, Cochrane Rehabilitation ( https://rehabilitation.cochrane.org/) could lead the way in supporting this methodological advance. 

Conflict of interest: The authors certify that there is no conflict of interest with any financial organization regarding the material discussed in the manuscript"

Funding: Royal Society Te Apārangi, New Zealand provided funding for the Catalyst meeting which formed the basis of the papers included in this special issue.

Authors' contributions: Kayes led the writing of the first concept proposal for this paper. All authors provided comment on this proposal. This was presented at the Catalyst meeting in Paris, July 2018 and discussed with attendees at this meeting. Pollock and Martin were in attendance and contributed to those discussions which informed the shape of the first full draft. Writing of the first full draft was led by Kayes, with all authors providing comment and suggestions to inform the final revised draft.

Acknowledgements: We acknowledge all those in attendance at the Catalyst meeting in Paris, July 2018 for their helpful comments and discussion which were formative to the final direction of this paper. 


\section{REFERENCES}

1. Morris ZS, Wooding S, Grant J. The answer is 17 years, what is the question: understanding time lags in translational research. Journal of the Royal Society of Medicine 2011;104(12):510-20. doi: 10.1258/jrsm.2011.110180

2. Bucknall T. Bridging the Know-Do Gap in Health Care through Integrated Knowledge Translation. Worldviews on Evidence-Based Nursing 2012;9(4):193-94. doi: doi:10.1111/j.1741-6787.2012.00263.x

3. Pakenham-Walsh N. Learning from one another to bridge the "know-do gap". BMJ 2004;329(7475):1189. doi: 10.1136/bmj.329.7475.1189

4. van den Driessen Mareeuw F, Vaandrager L, Klerkx L, et al. Beyond bridging the know-do gap: a qualitative study of systemic interaction to foster knowledge exchange in the public health sector in The Netherlands. BMC Public Health 2015;15(1):922. doi: $10.1186 / \mathrm{s} 12889-015-2271-7$

5. Walker MF, Fisher RJ, Korner-Bitensky N, et al. From What We Know to What We Do: Translating Stroke Rehabilitation Research into Practice. International Journal of Stroke 2013;8(1):11-17. doi: 10.1111/j.1747-4949.2012.00974.x

6. Cochrane collaboration. Cochrane Knowledge Translation Framework 2017 [Available from: http://community.cochrane.org/sites/default/files/uploads/inlinefiles/Cochrane $\% 20 \mathrm{Knowledge} \% 20$ Translation\%20Framework.pdf accessed 29 June 2018.

7. Cochrane collaboration. Cochrane Strategy to 2020 [accessed 28 February 2019.

8. Marquez C, Johnson AM, Jassemi S, et al. Enhancing the uptake of systematic reviews of effects: what is the best format for health care managers and policy-makers? A mixedmethods study. Implementation Science 2018;13(1):84. doi: 10.1186/s13012-0180779-9

9. Oliver K, Innvar S, Lorenc T, et al. A systematic review of barriers to and facilitators of the use of evidence by policymakers. BMC Health Services Research 2014;14(1):2. doi: $10.1186 / 1472-6963-14-2$

10. Oliver KA, de Vocht F. Defining 'evidence' in public health: a survey of policymakers' uses and preferences. European Journal of Public Health 2017;27(suppl_2):112-17. doi: 10.1093/eurpub/ckv082

11. Tricco AC, Cardoso R, Thomas SM, et al. Barriers and facilitators to uptake of systematic reviews by policy makers and health care managers: a scoping review. Implementation Science 2016;11(1):4. doi: 10.1186/s13012-016-0370-1 
12. Wallace J, Byrne C, Clarke M. Making evidence more wanted: a systematic review of facilitators to enhance the uptake of evidence from systematic reviews and metaanalyses. International Journal of Evidence-Based Healthcare 2012;10(4):338-46. doi: doi:10.1111/j.1744-1609.2012.00288.x

13. Wallace J, Nwosu B, Clarke M. Barriers to the uptake of evidence from systematic reviews and meta-analyses: a systematic review of decision makers' perceptions. BMJ Open 2012;2(5):e001220. doi: 10.1136/bmjopen-2012-001220

14. Pawson R, Greenhalgh T, Harvey G, et al. Realist review - a new method of systematic review designed for complex policy interventions. Journal of Health Services Research \& Policy 2005;10(1_suppl):21-34. doi: 10.1258/1355819054308530

15. Pollock A, Berge E. How to do a systematic review. International Journal of Stroke 2018;13(2):138-56. doi: 10.1177/1747493017743796

16. Pollock AM, Richard; Watts, Chris Involving People: A learning resource for systematic review authors 2018 [Available from: https://training.cochrane.org/involving-people accessed 27 February 2019.

17. Wong G, Greenhalgh T, Westhorp G, et al. Development of methodological guidance, publication standards and training materials for realist and meta-narrative reviews: the RAMESES (Realist And Meta-narrative Evidence Syntheses - Evolving Standards) project. Health Services and Delivery Research 2014;2(30)

18. Callard F, Rose D, Wykes T. Close to the bench as well as at the bedside: involving service users in all phases of translational research. Health Expectations 2012;15(4):389-400. doi: doi:10.1111/j.1369-7625.2011.00681.x

19. Brett J, Staniszewska S, Mockford C, et al. Mapping the impact of patient and public involvement on health and social care research: a systematic review. Health Expectations 2014;17(5):637-50. doi: doi:10.1111/j.1369-7625.2012.00795.x

20. Yarborough M, Edwards K, Espinoza P, et al. Relationships Hold the Key to Trustworthy and Productive Translational Science: Recommendations for Expanding Community Engagement in Biomedical Research. Clinical and Translational Science 2013;6(4):310-13. doi: doi:10.1111/cts.12022

21. Hoddinott P, Pollock A, O'Cathain A, et al. How to incorporate patient and public perspectives into the design and conduct of research [version 1; referees: 3 approved, 2 approved with reservations]. F1000Research 2018;7(752) doi:

10.12688/f1000research.15162.1 
22. Brandon PR, Fukunaga LL. The State of the Empirical Research Literature on Stakeholder Involvement in Program Evaluation. American Journal of Evaluation 2014;35(1):26-44. doi: 10.1177/1098214013503699

23. D. SN, Pablo DGJ, J. PLG, et al. Patient and service user engagement in research: a systematic review and synthesized framework. Health Expectations 2015;18(5):115166. doi: doi:10.1111/hex.12090

24. Deverka PA, Lavallee DC, Desai PJ, et al. Stakeholder participation in comparative effectiveness research: defining a framework for effective engagement. Journal of Comparative Effectiveness Research 2012;1(2):181-94. doi: 10.2217/cer.12.7

25. Oliver SR, Rees RW, Clarke-Jones L, et al. A multidimensional conceptual framework for analysing public involvement in health services research. Health Expectations 2008;11(1):72-84. doi: doi:10.1111/j.1369-7625.2007.00476.x

26. Peters DH, Bhuiya A, Ghaffar A. Engaging stakeholders in implementation research: lessons from the Future Health Systems Research Programme experience. Health Research Policy and Systems 2017;15(2):104. doi: 10.1186/s12961-017-0269-6

27. Thompson J, Barber R, Ward PR, et al. Health researchers' attitudes towards public involvement in health research. Health Expectations 2009;12(2):209-20. doi: doi:10.1111/j.1369-7625.2009.00532.x

28. Staniszewska S, Brett J, Mockford C, et al. The GRIPP checklist: Strengthening the quality of patient and public involvement reporting in research. International Journal of Technology Assessment in Health Care 2011;27(4):391-99. doi: 10.1017/S0266462311000481 [published Online First: 10/17]

29. Hanley B, Bradburn J, Barnes M, et al. Involving the public in NHS public health, and social care research: briefing notes for researchers. Eastleigh: INVOLVE 2004.

30. Public Involvement Standards Development Partnership. National Standards for Public Involvement [Available from: https://sites.google.com/nihr.ac.uk/pi-standards/home accessed 27 February 2019.

31. Hickey G, Brearley S, Coldham T. Guidance on co-producing a research project. Southampton: INVOLVE 2018.

32. Smith E, Ross F, Donovan S, et al. Service user involvement in nursing, midwifery and health visiting research: A review of evidence and practice. International Journal of Nursing Studies 2008;45(2):298-315. 
33. Braye S, Preston-Shoot M. Emerging from out of the shadows? Service user and carer involvement in systematic reviews. Evidence \& Policy: A Journal of Research, Debate and Practice 2005;1(2):173-94. doi: 10.1332/1744264053730743

34. Harris J, Croot L, Thompson J, et al. How stakeholder participation can contribute to systematic reviews of complex interventions. Journal of Epidemiology and Community Health 2015 doi: 10.1136/jech-2015-205701

35. Kiera K, Dwayne VE, Emma I. Stakeholder engagement opportunities in systematic reviews: Knowledge transfer for policy and practice. Journal of Continuing Education in the Health Professions 2008;28(2):67-72. doi: doi:10.1002/chp.159

36. Kreis J, Puhan MA, Schünemann HJ, et al. Consumer involvement in systematic reviews of comparative effectiveness research. Health Expectations 2013;16(4):323-37. doi: doi:10.1111/j.1369-7625.2011.00722.x

37. Pollock A, Campbell P, Struthers C, et al. Stakeholder involvement in systematic reviews: a protocol for a systematic review of methods, outcomes and effects. Research Involvement and Engagement 2017;3(1):9. doi: 10.1186/s40900-017-0060-4

38. INVOLVE. Public involvement in systematic review: Supplement to the briefing notes for researchers. Eastleigh: INVOLVE, 2012.

39. Pollock A, Campbell P, Struthers C, et al. Stakeholder involvement in systematic reviews: a scoping review. Systematic Reviews 2018;7(1):208. doi: 10.1186/s13643-018-08520

40. Cochrane collaboration. Consumer involvement in Cochrane - the Statement of Principles 2017 [Available from:

http://consumers.cochrane.org/sites/consumers.cochrane.org/files/public/uploads/state ment of principles_for_consumer_involvement in_cochrane july 2017.pdf accessed 04 July 2018.

41. Bastian H. The power of sharing knowledge: Consumer participation in the Cochrane Collaboration Cochrane Collaboration 1994

42. Morley RF, Norman G, Golder S, et al. A systematic scoping review of the evidence for consumer involvement in organisations undertaking systematic reviews: focus on Cochrane. Research Involvement and Engagement 2016;2(1):36. doi: 10.1186/s40900-016-0049-4

43. Kersten P, Ellis-Hill C, McPherson KM, et al. Beyond the RCT - understanding the relationship between interventions, individuals and outcome - the example of 
neurological rehabilitation. Disability and Rehabilitation 2010;32(12):1028-34. doi: $10.3109 / 09638281003775568$

44. DeJong G, Horn SD, Conroy B, et al. Opening the Black Box of Poststroke Rehabilitation: Stroke Rehabilitation Patients, Processes, and Outcomes. Archives of Physical Medicine and Rehabilitation 2005;86(12):1-7.

45. Glasziou P, Meats E, Heneghan C, et al. What is missing from descriptions of treatment in trials and reviews? BMJ 2008;336(7659):1472-74. doi:

10.1136/bmj.39590.732037.47

46. Hoffmann TC, Erueti C, Glasziou PP. Poor description of non-pharmacological interventions: analysis of consecutive sample of randomised trials. BMJ : British Medical Journal 2013;347:f3755. doi: 10.1136/bmj.f3755

47. Hoffmann TC, Walker MF, Langhorne P, et al. What's in a name? The challenge of describing interventions in systematic reviews: analysis of a random sample of reviews of non-pharmacological stroke interventions. BMJ Open 2015;5(11):e009051. doi: 10.1136/bmjopen-2015-009051

48. Santisteban L, Térémetz M, Bleton J-P, et al. Upper Limb Outcome Measures Used in Stroke Rehabilitation Studies: A Systematic Literature Review. PLOS ONE 2016;11(5):e0154792. doi: 10.1371/journal.pone.0154792

49. Craig P, Dieppe P, Macintyre S, et al. Developing and evaluating complex interventions: the new Medical Research Council guidance. BMJ 2008;337:a1655. doi: 10.1136/bmj.a1655

50. World Health Organisation. International classification of functioning, disability, and health : ICF (Version 1.0.). Geneva: World Health Organization 2001.

51. Boote J, Baird W, Sutton A. Public involvement in the systematic review process in health and social care: A narrative review of case examples. Health Policy 2011;102(2):105-16. doi: https://doi.org/10.1016/j.healthpol.2011.05.002

52. Saan MC, Boeije HR, Sattoe JNT, et al. Recording and Accounting for Stakeholder Involvement in Systematic Reviews. Health Information \& Libraries Journal 2015;32(2):95-106. doi: doi:10.1111/hir.12099

53. Staniszewska S, Brett J, Simera I, et al. GRIPP2 reporting checklists: tools to improve reporting of patient and public involvement in research. Research Involvement and Engagement 2017;3(1):13. doi: 10.1186/s40900-017-0062-2

54. Pollock A, Campbell P, Baer G, et al. User involvement in a Cochrane systematic review: using structured methods to enhance the clinical relevance, usefulness and usability of 
a systematic review update. Systematic Reviews 2015;4(1):55. doi: 10.1186/s13643015-0023-5

55. Cullen KL, Irvin E, Collie A, et al. Effectiveness of Workplace Interventions in Returnto-Work for Musculoskeletal, Pain-Related and Mental Health Conditions: An Update of the Evidence and Messages for Practitioners. Journal of Occupational Rehabilitation 2018;28(1):1-15. doi: 10.1007/s10926-016-9690-х

56. Synnot A, Bragge P, Lowe D, et al. Research priorities in health communication and participation: international survey of consumers and other stakeholders. BMJ Open 2018;8(5) doi: 10.1136/bmjopen-2017-019481

57. Hill S, Synnot A, O'Sullivan M, et al. Research Priority Setting: Setting priorities for Cochrane Reviews on consumer and communication topics [Available from: https://www.latrobe.edu.au/chcp/projects/research-priority-setting accessed 27 February 2019.

58. Martin S, Fleming J, Cullum S, et al. Exploring attitudes and preferences for dementia screening in Britain: contributions from carers and the general public. BMC Geriatrics 2015;15(1):110. doi: 10.1186/s12877-015-0100-6

59. Young AE, Wasiak R, Roessler RT, et al. Return-to-Work Outcomes Following Work Disability: Stakeholder Motivations, Interests and Concerns. Journal of Occupational Rehabilitation 2005;15(4):543-56. doi: 10.1007/s10926-005-8033-0

60. Beresford P. Beyond the Usual Suspects. London: Shaping Our Lives, 2013.

61. Green LW, Glasgow RE, Atkins D, et al. Making Evidence from Research More Relevant, Useful, and Actionable in Policy, Program Planning, and Practice: slips "twixt Cup and lip". American Journal of Preventive Medicine 2009;37(6):S187-S91. doi: 10.1016/j.amepre.2009.08.017

62. Green LW, Ottoson JM, García C, et al. Diffusion Theory and Knowledge Dissemination, Utilization, and Integration in Public Health. Annual Review of Public Health 2009;30(1):151-74. doi: 10.1146/annurev.publhealth.031308.100049

63. Greenhalgh T, Robert G, Macfarlane F, et al. Diffusion of Innovations in Service Organizations: Systematic Review and Recommendations. The Milbank Quarterly 2004;82(4):581-629. doi: doi:10.1111/j.0887-378X.2004.00325.x

64. Lenfant C. Clinical Research to Clinical Practice — Lost in Translation? New England Journal of Medicine 2003;349(9):868-74. doi: 10.1056/NEJMsa035507 
65. Marchal B, Westhorp G, Wong G, et al. Realist RCTs of complex interventions - An oxymoron. Social Science \& Medicine 2013;94:124-28. doi: https://doi.org/10.1016/j.socscimed.2013.06.025

66. Greenhalgh T, Papoutsi C. Studying complexity in health services research: desperately seeking an overdue paradigm shift. BMC Medicine 2018;16(1):95. doi: $10.1186 / \mathrm{s} 12916-018-1089-4$

67. Greenhalgh T, Malterud K. Systematic Reviews for Policymaking: Muddling Through. American Journal of Public Health 2017;107(1):97-99. doi: 10.2105/ajph.2016.303557

68. Lavis JN, Davies HTO, Gruen RL, et al. Working within and beyond the Cochrane Collaboration to make systematic reviews more useful to healthcare managers and policy makers. Healthcare policy = Politiques de sante 2006;1(2):21-33.

69. Snilstveit B. Systematic reviews: from 'bare bones' reviews to policy relevance. Journal of Development Effectiveness 2012;4(3):388-408. doi: $10.1080 / 19439342.2012 .709875$

70. Pollock A, St George B, Fenton M, et al. Top 10 Research Priorities Relating to Life after Stroke - Consensus from Stroke Survivors, Caregivers, and Health Professionals. International Journal of Stroke 2014;9(3):313-20. doi: 10.1111/j.17474949.2012.00942.x

71. Monaghan M, Boaz A. Chapter 10. Evidence from realist research, it's influence and impact. In: Emmel N, Greenhalgh, J., Manzano, A., Monaghan, M., \& Dalkin, S., ed. Doing Realist Research. London: Sage 2018.

72. Fletcher A, Jamal F, Moore G, et al. Realist complex intervention science: Applying realist principles across all phases of the Medical Research Council framework for developing and evaluating complex interventions. Evaluation 2016;22(3):286-303. doi: $10.1177 / 1356389016652743$

73. Harden A, Thomas J, Cargo M, et al. Cochrane Qualitative and Implementation Methods Group guidance series - paper 5: methods for integrating qualitative and implementation evidence within intervention effectiveness reviews. Journal of Clinical Epidemiology 2018;97:70-78. doi: https://doi.org/10.1016/j.jclinepi.2017.11.029

74. Trisha G, Sally T, Kirsti M. Time to challenge the spurious hierarchy of systematic over narrative reviews? European Journal of Clinical Investigation 2018;48(6):e12931. doi: doi:10.1111/eci.12931 
75. Emmel N, Greenhalgh, J., Manzano, A., Monaghan, M., \& Dalkin, S. Introduction: Doing realisty evaluation, synthesis and research. In: Emmel N, Greenhalgh, J., Manzano, A., Monaghan, M., \& Dalkin, S., ed. Doing Realist Research. London: Sage 2018.

76. Dalkin SM, Greenhalgh J, Jones D, et al. What's in a mechanism? Development of a key concept in realist evaluation. Implementation Science 2015;10(1):49. doi: $10.1186 / \mathrm{s} 13012-015-0237-\mathrm{x}$

77. Shaw J, Gray CS, Baker GR, et al. Mechanisms, contexts and points of contention: operationalizing realist-informed research for complex health interventions. $B M C$ Medical Research Methodology 2018;18(1):178. doi: 10.1186/s12874-018-0641-4

78. Rycroft-Malone J, McCormack B, Hutchinson AM, et al. Realist synthesis: illustrating the method for implementation research. Implementation Science 2012;7(1):33. doi: $10.1186 / 1748-5908-7-33$

79. Kristjansson B, Petticrew M, MacDonald B, et al. School feeding for improving the physical and psychosocial health of disadvantaged students. Cochrane Database of Systematic Reviews 2007(1) doi: 10.1002/14651858.CD004676.pub2

80. Greenhalgh T, Kristjansson E, Robinson V. Realist review to understand the efficacy of school feeding programmes. BMJ 2007;335(7625):858-61. doi: 10.1136/bmj.39359.525174.AD

81. Whitaker R, Hendry M, Aslam Rh, et al. Intervention Now to Eliminate Repeat Unintended Pregnancy in Teenagers (INTERUPT): a systematic review of intervention effectiveness and cost-effectiveness, and qualitative and realist synthesis of implementation factors and user engagement. Health technology assessment 2016;20(16):1-214. doi: 10.3310/hta20160

82. Whitaker R, Hendry M, Booth A, et al. Intervention Now To Eliminate Repeat Unintended Pregnancy in Teenagers (INTERUPT): a systematic review of intervention effectiveness and cost-effectiveness, qualitative and realist synthesis of implementation factors and user engagement. BMJ Open 2014;4(4):e004733. doi: 10.1136/bmjopen-2013-004733

83. Roberts JL, Din NU, Williams M, et al. Development of an evidence-based complex intervention for community rehabilitation of patients with hip fracture using realist review, survey and focus groups. BMJ Open 2017;7(10):e014362. doi:

10.1136/bmjopen-2016-014362 
84. Levack WMM, Kayes NM, Fadyl JK. Experience of recovery and outcome following traumatic brain injury: a metasynthesis of qualitative research. Disability and Rehabilitation 2010;32(12):986-99. doi: 10.3109/09638281003775394

85. Dijkers MP, Murphy SL, Krellman J. Evidence-Based Practice for Rehabilitation Professionals: Concepts and Controversies. Archives of Physical Medicine and Rehabilitation 2012;93(8, Supplement):S164-S76. doi: https://doi.org/10.1016/j.apmr.2011.12.014

86. Brown HE, Atkin AJ, Panter J, et al. Family-based interventions to increase physical activity in children: a systematic review, meta-analysis and realist synthesis. Obesity Reviews 2016;17(4):345-60. doi: doi:10.1111/obr.12362

87. Hart T WJ, Dijkers M, Packel A, Turkstra L, Zanca J, Ferraro M, Chen C, Van Stan J. Manual of Rehabilitation Treatment Specification [Available from: http://mrri.org/innovations/manual-for-rehabilitation-treatment-specification/ accessed 27 February 2019.

88. Siegert RJ, McPherson KM, Dean SG. Theory development and a science of rehabilitation. Disability and Rehabilitation 2005;27(24):1493-501. doi: $10.1080 / 09638280500288401$

89. Hoffmann T, Bennett S, Del Mar C. Evidence-Based Practice Across the Health Professions 3rd Edition 3rd ed: Elsevier 2017.

90. Sackett DL, Rosenberg WMC, Gray JAM, et al. Evidence based medicine: what it is and what it isn't. $B M J$ 1996;312(7023):71-72. doi: 10.1136/bmj.312.7023.71 
Box 1: Pollock et al. ${ }^{54}$

Purpose: Update review (previously published 2003, 2007) exploring effectiveness of physical rehabilitation approaches in recovery of function and mobility for people with stroke Stakeholders: Stroke survivors $(n=3)$, Carers $(n=1)$, and physiotherapists $(n=9)$. In addition, four review authors (physiotherapy educators) were present, but did not vote.

Approach to stakeholder involvement: Drew on Boote et al. $(2011)^{51}$ recommendations to pre-plan three stakeholder group meetings. Stakeholders discussed and agreed a set of meeting 'rules'. Stakeholders were given "control" over a number of specific decisions relating to the review. Each meeting followed a structured approach drawing on nominal group techniques to reach consensus (e.g. introduction-discussion-vote-vote count). Meetings were audio-recorded and transcribed. There were a number of opportunities for stakeholder input between meetings to address specific issues.

Stakeholder input: Intervention categorisation, strategies to update, clinical implications, and develop and support dissemination plan

Resourcing: Expenses (travel, food) were covered, but stakeholders were not paid for their time. A part time researcher was appointed and responsible for overseeing user involvement. 
Box 2: Cullen et al. ${ }^{55}$

Purpose: Update review (previously published 2010) synthesising evidence on the effectiveness of workplace-based return to work interventions and work disability management interventions for workers with musculoskeletal, pain-related, and mental health conditions.

Stakeholders: Injury workers advocacy groups, unions, workplaces, and health and safety associations. Number not reported.

Approach to stakeholder involvement: Drew on Keown et al. $(2008)^{35}$ recommendations. Stakeholder meetings held on multiple occasions throughout the review process in each research location. The exact process of these meetings was not explicitly described, but Keown et al. recommends a number of opportunities for stakeholder involvement including topic consultation, stakeholder input into methods, reaction to findings, and dissemination activities.

Stakeholder input: Question development, search terms, operational definitions, workplacebased interventions categories, message content, potential audiences.

Resourcing: Not reported. 
Box 3: Brown et al. ${ }^{86}$

Purpose: Examine existing interventions to assist those developing family-based interventions to encourage uptake and maintenance of physical activity in children.

Design: A dual meta-analysis and realist synthesis

Justification of approach: Given complexity of relevant evidence, it was argued that a multi-faceted approach would yield more useful conclusions.

Stakeholder involvement: Not specified.

Search strategy: Broad search strategy aiming to identify family-based programmes (intervention), targeting children aged 5 to 12 years (population), which included a measure of physical activity (outcome) without limiting by study design.

Included studies: Each review component had eligibility criteria specific to their aim and purpose. The meta-analysis aimed to determine overall effect, and so was limited to papers which had sufficient data on effect. The realist review aimed to explore what works, for whom, in what circumstances, how and why, and included all papers identified which met the inclusion criteria with respect to the intervention, population and outcome of interest.

Data extraction: For the meta-analysis, data extraction focused on measure of effect and precision. For the realist review, data were extracted if they met pre-determined principles of relevance and rigour, and focused on the development of CMO configurations.

Output: A clear articulation of effect, augmented with key recommendations for policy and practice regarding tailoring to context and specific strategies to optimise the effectiveness of family-based interventions for physical activity in children. 
Table I: Mapping Cochrane KT Strategy and Framework ${ }^{6}$ to Stakeholder involvement and theory-based, mixed methods review design

\begin{tabular}{|c|c|c|c|}
\hline Key theme & Theme Description & Stakeholder involvement & $\begin{array}{l}\text { Theory-based, mixed methods } \\
\text { review design }\end{array}$ \\
\hline $\begin{array}{l}\text { Prioritisation and co- } \\
\text { production }\end{array}$ & $\begin{array}{l}\text { Producing reviews which } \\
\text { meet the needs of users }\end{array}$ & $\begin{array}{l}\text { Engaging stakeholders in research } \\
\text { prioritisation strategies, and/or } \\
\text { involving them early in review } \\
\text { processes so they can contribute to } \\
\text { refining the review question will } \\
\text { mean reviews are more likely meet } \\
\text { the needs of users. Further, the } \\
\text { review findings will be more likely } \\
\text { to be timely, in that they are asking } \\
\text { questions important to stakeholders } \\
\text { at that time. }\end{array}$ & $\begin{array}{l}\text { Reviews which move beyond } \\
\text { questions of effectiveness (e.g. What } \\
\text { works? Does it work?) to questions } \\
\text { relevant to implementation and } \\
\text { context (How does it work? Why } \\
\text { does it work? Under what conditions } \\
\text { is it most effective? Who is most } \\
\text { likely to benefit?) will be more } \\
\text { likely to meet the needs of users. }\end{array}$ \\
\hline Packaging/push & $\begin{array}{l}\text { Ensuring users receive } \\
\text { and can act on our } \\
\text { reviews and products }\end{array}$ & $\begin{array}{l}\text { Engaging stakeholders in } \\
\text { interpreting and making sense of } \\
\text { review findings and informing how } \\
\text { the findings are framed will mean } \\
\text { review findings are more accessible } \\
\text { and usable. }\end{array}$ & $\begin{array}{l}\text { Reviews which focus not only on } \\
\text { average effects in a tightly defined } \\
\text { population, but which also articulate } \\
\text { context-mechanism-outcome (CMO) } \\
\text { configurations will help users to } \\
\text { determine relevance to local context } \\
\text { and act accordingly. }\end{array}$ \\
\hline Facilitating push & $\begin{array}{l}\text { Growing users' capacity } \\
\text { to find and use reviews }\end{array}$ & $\begin{array}{l}\text { Involving stakeholders in the review } \\
\text { production and dissemination } \\
\text { processes will support user } \\
\text { capabilities to access, engage with } \\
\text { and understand review findings. }\end{array}$ & $\begin{array}{l}\text { Developing reviews which can be } \\
\text { applied to local context will make } \\
\text { review findings more usable. }\end{array}$ \\
\hline Exchange & $\begin{array}{l}\text { Engaging with our users } \\
\text { to support their evidence } \\
\text { informed decision } \\
\text { making }\end{array}$ & $\begin{array}{l}\text { When stakeholders are involved } \\
\text { from the outset, exchange is inherent } \\
\text { in the review process. Further, } \\
\text { working with stakeholders to } \\
\text { disseminate findings can also aid }\end{array}$ & $\begin{array}{l}\text { Not explicit in theory-based, mixed } \\
\text { methods review design. }\end{array}$ \\
\hline
\end{tabular}




\begin{tabular}{|c|c|c|c|}
\hline & & $\begin{array}{l}\text { their evidence informed decision } \\
\text { making. }\end{array}$ & \\
\hline $\begin{array}{l}\text { Improving } \\
\text { climate/building } \\
\text { demand }\end{array}$ & $\begin{array}{l}\text { Advocating for evidence } \\
\text { informed health decision- } \\
\text { making }\end{array}$ & $\begin{array}{l}\text { Routinely involving stakeholders in } \\
\text { reviews can improve the research } \\
\text { climate generally given widespread } \\
\text { acceptance that stakeholders have a } \\
\text { moral right to be involved. In } \\
\text { addition, stakeholders who have } \\
\text { been involved can become } \\
\text { advocates for evidence informed } \\
\text { decision making in the future. }\end{array}$ & $\begin{array}{l}\text { The cumulative experience of } \\
\text { engaging with reviews which are } \\
\text { more relevant and usable in the local } \\
\text { context, and which have the } \\
\text { information needed to act, will } \\
\text { likely increase trust and confidence, } \\
\text { and therefore advocacy, for reviews. }\end{array}$ \\
\hline
\end{tabular}

